*** This is the authors'version - the final version is available via the journal website https://www.sciencedirect.com/journal/government-information-quarterly ***

Special issue editorial

\title{
Public value creation in digital government
}

\author{
Panos Panagiotopoulos, Bram Klievink, Antonio Cordella
}

\begin{abstract}
Public value theory offers innovative ways to plan, design, and implement digital government initiatives. The theory has gained the attention of researchers due to its powerful proposition that shifts the focus of public sector management from internal efficiency to value creation processes that occur outside the organization. While public value creation has become the expectation that digital government initiatives have to fulfil, there is lack of theoretical clarity on what public value means and on how digital technologies can contribute to its creation. The special issue presents a collection of six papers that provide new insights on how digital technologies support public value creation. Building on their contributions, the editorial note conceptualizes the realm of public value creation by highlighting: (1) the integrated nature of public value creation supported by digital government implementations rather than enhancing the values provided by individual technologies or innovations, (2) how the outcome of public value creation is reflected in the combined consumption of the various services enabled by technologies and (3) how public value creation is enabled by organizational capabilities and configurations.
\end{abstract}

\section{Introduction}

Public value theory shifts the focus of public sector management from within the organizational boundaries to society - from how to better produce public services to how to deliver public services that better satisfy those who will consume them. The diffusion of digital technologies has fostered this transition and created a powerful argument for public value creation as the ultimate aim of digital government initiatives. Public value theory has been particularly successful in providing an alternative to New Public Management's narrative that conceives digital technologies as tools of administrative efficiency. Instead, public value management provides a more encompassing view to account for the complex transformations required to shift the focus from service production to the fulfilment of public expectations and goals (Bannister $\&$ Connolly, 2014; Cordella \& Bonina, 2012). 
Public value theory as in Moore's (1995) original work does not directly account for digital government but provides a solid foundation to study the transformation fostered by digital technologies in public management. Digital government in fact transforms the ways in which public sector organizations produce and deliver services and interact with citizens. These transformations are mediated by digital technologies but also by organizational and institutional factors. Moore's (1995) approach suggests that public management strategies devoted to public value creation do not only need specific organizational capabilities and resources to deliver services that fulfil social expectations but also need to be politically legitimate and sustainable (Alford \& Hughes, 2008). To be able to adapt to these transformations and better fulfil social expectations and needs, public sector organizations need to acquire or develop capabilities that will enable them to exploit the opportunities and mitigate the challenges associated with digital government initiatives.

On a broader scale, public value theory views governments and public managers as catalysts, guarantors and active agents of public value creation in line with social expectations (Bryson, Crosby, \& Bloomberg, 2014). Researchers in public administration have been drawing on public value theory as an analytical concept to illustrate public sector practice and as a normative approach that views public value as a driver for service improvement (Williams \& Shearer, 2011). Respectively, the theory has provided a rich context in which to reconsider the significant role of public managers and how digital government reforms should be assessed from a valueoriented perspective (Bannister \& Connolly, 2014; Cordella \& Bonina, 2012; Pang, Lee, \& DeLone, 2014; Rose, Persson, Heeager, \& Irani, 2015).

While these perspectives have established the relevance of public value, understanding and measuring how digital government projects create public value still remain to be explored. More than ever, digital government projects have to meet high levels of social expectations in public value creation while facing increased levels of complexity and integration challenges. This has been especially reinforced by the use of front facing and interactive technologies like social media, data distribution tools and platform-based architectures. Their applications in open data and open government, data analytics, smart cities, services co-production and many other areas have been associated with public value creation (Chatfield \& Reddick, 2018; Cordella \& Willcocks, 2012; Pereira, Macadar, Luciano, \& Testa, 2017; Y1ldı \& Saylam, 2013). Overall, they have reshaped the challenges, complexity of processes, and expectations that public sector organizations have to face when public value creation is concerned.

Our motivation for developing this special issue is to provide a consolidated and comprehensive point of reference for research in digital government that builds on public value theory. Public value theory is in fact increasingly referred to in digital government research but there is still lack of theoretical clarity on what public value means and on how digital technologies can contribute to its creation. This special issue aims at bringing this clarity and offering a point of departure for more nuanced and focused research on public value in digital government. Special issues in digital government have been motivated, for example, by the need to establish emerging concepts (e.g. Kankanhalli, Zuiderwijk, \& Tayi, 2017; Mergel, Gong, \& Bertot, 2018) or to bring 
together a collection of research about new technologies of interest in academic communities (e.g. Criado, Sandoval-Almazan, \& Gil-Garcia, 2013; Kankanhalli, Charalabidis, \& Mellouli, 2019). Establishing theoretical clarity can be both challenging and rewarding within an applied interdisciplinary field that has been criticized for its lack of theoretical development (Bannister $\&$ Connolly, 2015). We hope that the special issue will make researchers and public managers even more confident to bring public value to the forefront of their analytical practice.

The rest of the editorial note provides a think piece aiming to stimulate further discussion on the nature of public value creation in digital government. We start with a brief background to frame existing approaches and challenges that lead to two main points of departure: the importance of an integrated approach and the enabling role of organizational capabilities. This leads to the presentation of our conceptual framework that depicts the realm of public value creation and highlights the boundaries between public value and its enablers. This is followed by an introduction to the articles published in the special issue that touch upon diverse aspects of public value creation. The six articles, each with their own aims and contexts, provide a collection of contributions to our understanding of value and public value. We conclude by offering further reflections and ideas for future research.

\section{The realm of public value creation in digital government}

The increasing interest of digital government in public value theory is a response to the difficulties in fulfilling citizens' expectations in public service delivery following the lack of success of New Public Management reforms (Cordella \& Bonina, 2012). Several contributions to the field exemplified how public value theory can help to rethink public service provision in digital government and to reconsider the implications these developments have for public management. While the concept of public value has received almost unanimous consensus, what actually constitutes public value in digital government is still debated. Bannister and Connolly (2014) propose a taxonomy of public sector values to frame the complex notion of public value and argue about the impact of each value on digital government initiatives (e.g. transparency, efficiency, inclusiveness). Bannister and Connolly (2014) drew on the comprehensive typology by Jorgensen and Bozeman (2007) that identified an inventory of 72 values that public sector organizations can deliver to lead to the generation of public value.

Public value has been seen as a source of critical factors, benchmarking and analytical frameworks to evaluate public services and the impact of technologies on service production and provision (e.g. Karkin \& Janssen, 2013; Karunasena \& Deng, 2012; Scott, DeLone, \& Golden, 2016). Values can be assessed and quantified on the outcome of digital services to facilitate comparisons and priorities among different provisions; for example, to cluster values and link them to operational characteristics of government websites (Scott et al., 2016). To refocus the theory as an applied lens, Rose et al. (2015) distinguish the professionalism, efficiency, service and engagement ideals as fundamental value positions that public managers apply in their digital 
government practice. Rose, Flak, and Sæbø (2018) re-approach value positions as a reflection of 'interest' and therefore suitable for explanatory analyses in combination with stakeholder theory.

Whether viewed as an evaluation framework or interpretive lens, studies have made the case for the multiplicity of values that drive public managers' actions and strategies. Respectively, digital technologies are a key component of public value creation both as enablers and as carriers of value propositions (Cordella \& Iannacci, 2010). Digital technologies make more effective the operationalization of managerial values, such as transparency, accountability, efficiency but also democratic values such as equality, openness, and fairness. While the analysis of the impact of digital government initiatives on individual value creation activities has led to useful insights, it does not sufficiently account for the complex and intertwined relationships among different services and the values they deliver. We point to an integrated perspective on public value creation with respect to its underlying enablers like technologies, resources and organizational capabilities. This is indeed needed to account for the complex factors that shape the impact of digital technologies on the production, delivery and consumption of public services and the public value this consumption creates.

Our motivation for this new perspective comes from the theory's foundations and developments in digital government. Moore's (1995) emphasis on the interlinked nature of organizational capabilities and public value creation has received less attention in digital government at the priority of conceptualizing public value and classifying its fundamental proponents. While digital government theory and practice have been maturing, the complexity of current digital initiatives has exponentially increased. As a consequence, policy makers and public managers have to master new approaches, demands and potential new roles to exploit public value creation opportunities (Janssen \& Helbig, 2016). Public officials can create infrastructures to stimulate public value creation in more or less deliberate ways (e.g. ease of online access, data distribution, mobile applications) or they might explicitly take on new roles where they orchestrate but do not maintain complete control of policy making and value creation processes (Janssen \& Helbig, 2016; Linders, 2012). Outside digital government, there have been calls for the public sector to more actively create value instead of facilitating its distribution within the conventional boundaries of public management (Kattel \& Mazzucato, 2018; Mazzucato \& Ryan-Collins, 2019).

Regardless of how proactive public organizations have been, they are faced with a plethora of digital solutions that multiply opportunities for public value creation while increasing the complexity of the processes that they have to undertake to create this value. Public managers are usually expected to implement and manage a range of digital innovations at the forefront of public value creation under resource, administrative, institutional and other constrains. Each of these implementations is associated with a value creation journey that needs to fulfil different policy goals, aims, indicators and processes (e.g. service use, public engagement, performance metrics). The forms and types of value that each digital initiative might yield can vary depending on expectations and/or outcomes. For example, initiatives like open data or hackathons provide infrastructures for public value creation but their outcomes are neither predictable nor 
guaranteed. When viewed in isolation and with respect to their individual outcomes, digital initiatives might provide an incomplete understanding of how value is created, consumed and underpinned by the organizational capabilities required to manage them. Therefore, the path between digital technologies, their value and public value should not be seen as straightforward. We conceptualize this approach in section 2.3 after elaborating on our two main points of departure on integrated public value creation (section 2.1) and organizational capabilities (section 2.2).

\subsection{Integrated public value creation}

Public value creation can be considered the outcome of a production process of different public services pursued by public agencies to fulfil the collective goals that citizens define in the democratic process of political elections - i.e. that are politically legitimated and sustainable (Benington \& Moore, 2010; Dahl \& Soss, 2014). Since public value entails different values, such as democratic and managerial values (Bonina \& Cordella, 2008), its creation involves a variety of administrative processes to guarantee that public value is created when the values generated by the combined consumption of public services are balanced (Cordella, Paletti, \& Shaikh, 2017). Therefore, effective public value creation requires to define what needs to be delivered further to a managerial strategy to enable its provision.

However, collective goals do not create public value as simply the sum of goals fulfilled by individual public services ${ }^{1}$. Public value is indeed created by the consumption of aggregated public services that are produced and provided using multiple digital technologies. Citizens do not value services per se but rather value what services deliver when consumed. Moreover, citizens consume services in aggregate and value what is delivered by the consumption of the aggregated services and not the sum of the values delivered by the consumption of the individual services (Cordella \& Paletti, 2018; Cordella, Paletti, \& Shaikh, 2017). Thus, public value is the trade-off that results from the balance of multiple public services that are consumed collectively and not as individual units (Benington, 2007; Hartley, Alford, Knies, \& Douglas, 2017). Public managers are continuously considering how to produce the individual services while having to balance the effects that each service has on other services (Cordella \& Paletti, 2018; Cordella, Paletti, \& Shaikh, 2017) to avoid negative impacts on the collective goals that are fulfilled when public services are consumed together (De Jong et al., 2017). At the very least, this becomes necessary due to limitations in technical capabilities and resources. Moreover, citizens' aspirations can vary over time which makes difficult to frame public services that can fulfil social expectations continuously (Bruijn \& Dicke, 2006; Moore \& Khagram, 2004; Zuboff \& Maxmin, 2002).

\footnotetext{
${ }^{1}$ We take a broad view of services to account for all the transactional and policy making outcomes that public sector organizations have a mandate to deliver to their publics.
} 
To better address changing citizen expectations, public administrations have increasingly relied upon digital innovations to deliver services. The effective support that digital technologies provide to public value creation is the outcome of two separate effects: (1) increasing the value that each single public service delivers and, at the same time, (2) maximizing the value that all the consumption of public services delivers together. The latter is what mostly determines public value creation but has not been addressed as such from an integrated perspective. Digital applications are solutions to better deliver individual services but also instruments to balance the value that individual services deliver so that the trade-offs among all public services provided to society is positive and the best possible that available resources permit (Cordella et al., 2017).

Isolated public value creation becomes even more prominent with technologies that promise significant benefits that are not straightforward to realize. For example, developments in new forms of data, big data and analytics are commonly assessed or even defined in terms of their perceived value (Günther, Rezazade Mehrizi, Huysman, \& Feldberg, 2017; McAfee \& Brynjolfsson, 2012). Not all advanced data applications can be directly associated with value or their value is not always evident - the least because this value is manifested in ways beyond the scope of traditional uses of data (e.g. optimization, economic benefits). Similarly, while big and open data applications can produce value in the form of benefit realization at different levels in government, the value they create together might be difficult to determine. New values can also be created when advances in government data science and artificial intelligence deliver benefits or potential use cases to governments, regulatory agencies and citizens (e.g. UK Government, 2019a). While the benefits on digital service design, regulatory compliance or organizational efficiency can be evident, the overall effects of these new applications are difficult to assess.

Consequently, many factors and contingent variables shape the net aggregate value delivered by public services. Even when these new applications can be managed in an integrated way, replicating value creation processes can be particularly challenging without consideration to organizational capabilities. For example, organizational capabilities are hard to develop and sustain while tending to be fragmented across and within government department and their large units due to variations in resources, skills and other components. This leads to our second major point: the interlinked nature of public value creation and organizational capabilities.

\subsection{Organizational capabilities for public value creation}

Drawing attention to the enablers of public value creation taps directly into Moore's (1995) original approach that emphasized strategic and operational aspects of public value management and their underpinning capabilities. These aspects include resource deployment, strategic planning, conceptualizing citizen groups and their characteristics, and several other pragmatic issues that are equally significant to the theory's political, philosophical and ethical underpinnings (Moore, 2014). Moore (1995) considered resource configurations and 
organizational capabilities as central to public value management but the capabilities required to enable digital government initiatives are often overlooked ${ }^{2}$.

While resource configurations and organizational capabilities have been related to digital public sector transformation, few studies have made the link someway explicit as a priority, outcome or process (Klievink, Bharosa, \& Tan, 2016; Klievink \& Janssen, 2009; Niehaves, Plattfaut, \& Becker, 2013; Pang et al., 2014). Other approaches like the business model concept focus on the connection between value propositions offered by digital government initiatives and their enablers but do not refer to public value creation as such (Panagiotopoulos, Al-Debei, Fitzgerald, \& Elliman, 2012). A notable exception is Pang et al. (2014) who theorize on the relationship between IT resources, organizational capabilities and public value creation. They identify the five capabilities that underpin this relationship as: public service delivery, public engagement, co-production, resource-building, and public-sector innovation capability.

The organizational capabilities identified by Pang et al. (2014) belong to dynamic capabilities and are distinct from operational capabilities which refer to the systematic use of resources to perform essential tasks and execute business processes. Dynamic capabilities are motivated by the resource-based view of the firm and indicate the ability to integrate, build, and reconfigure resources and competences to adapt to changes (Eisenhardt \& Martin, 2000; Teece, Pisano, Shuen, \& David Teece, 1997). Dynamic capabilities become increasingly relevant when the public sector has to respond to rapidly changing environments which, among other things, require learning and experimentation (Pablo, Reay, Dewald, \& Casebeer, 2007). In the popular transformation and stage models, dynamic capabilities have been seen as preconditions of transitions between stages and what eventually enables pathways to digital government realization (Klievink \& Janssen, 2009).

More recently, the strategic management literature recognized the importance of new public sector capabilities in the pursuit of enhanced public value creation (Cabral, Mahoney, McGahan, \& Potoski, 2019; Kattel \& Mazzucato, 2018). Cabral et al. (2019) identified stakeholder management capabilities among public, private, and non-profit organizations as critical to public value creation. Kattel and Mazzucato (2018) posit that dynamic capabilities are the missing element for the public sector to be genuinely seen as creating value in the economy instead of only facilitating or redistributing value. Cabral et al. (2019) and Kattel and Mazzucato (2018) support the wider view of the public sector as orchestrator of collaboration in public value creation (Crosby, 't Hart, \& Torfing, 2017).

The need to consider organizational capabilities as a critical path to public value creation is even more prevalent in an increasingly complex digital government landscape. Successful examples suggest how critical organizational capabilities are to creating and sustaining public value.

\footnotetext{
${ }^{2}$ Our approach to capabilities refers to strategic capabilities at the organizational level. This should not to be confused with other uses of the word capability, for example, in the context of technical capabilities, maturity models or competencies (e.g. Andersen \& Henriksen 2006; Estevez, \& Janowski 2013).
} 
Strong reflection of this are government portals and national service teams that were revamped to meet demands for centralized capability development across government departments (Mergel, 2019). For example, the Government Digital Service in the UK focused its approach on replicable capabilities that can enable integrated digital service design in areas such as modularization of website components, standardization of service design processes and user experience research (e.g. UK Government Digital Service, 2019b, 2019a, 2019c). To achieve these results, different mechanisms of developing capabilities had to be considered such as resource acquisition (e.g. expertise from the industry) and transferring resources or leveraging skills from one service area to another (e.g. creating digital service teams within large departments). Similar initiatives are being implemented in the areas of data science, artificial intelligence and policy analytics where capability development has to rely even less on external acquisition via recruitment and more on leveraging resources and expertise within government networks (UK Government, 2019b).

\subsection{Conceptual framework}

Informed by the above discussion, the conceptual framework shown in figure 1 presents the complex domain of public value creation in digital government. The framework links the different processes by which public services are produced, the impact that technologies have on the production of these services, the organizational capabilities needed to coordinate and manage service production processes and the integrated outcome of public value creation when services are consumed.

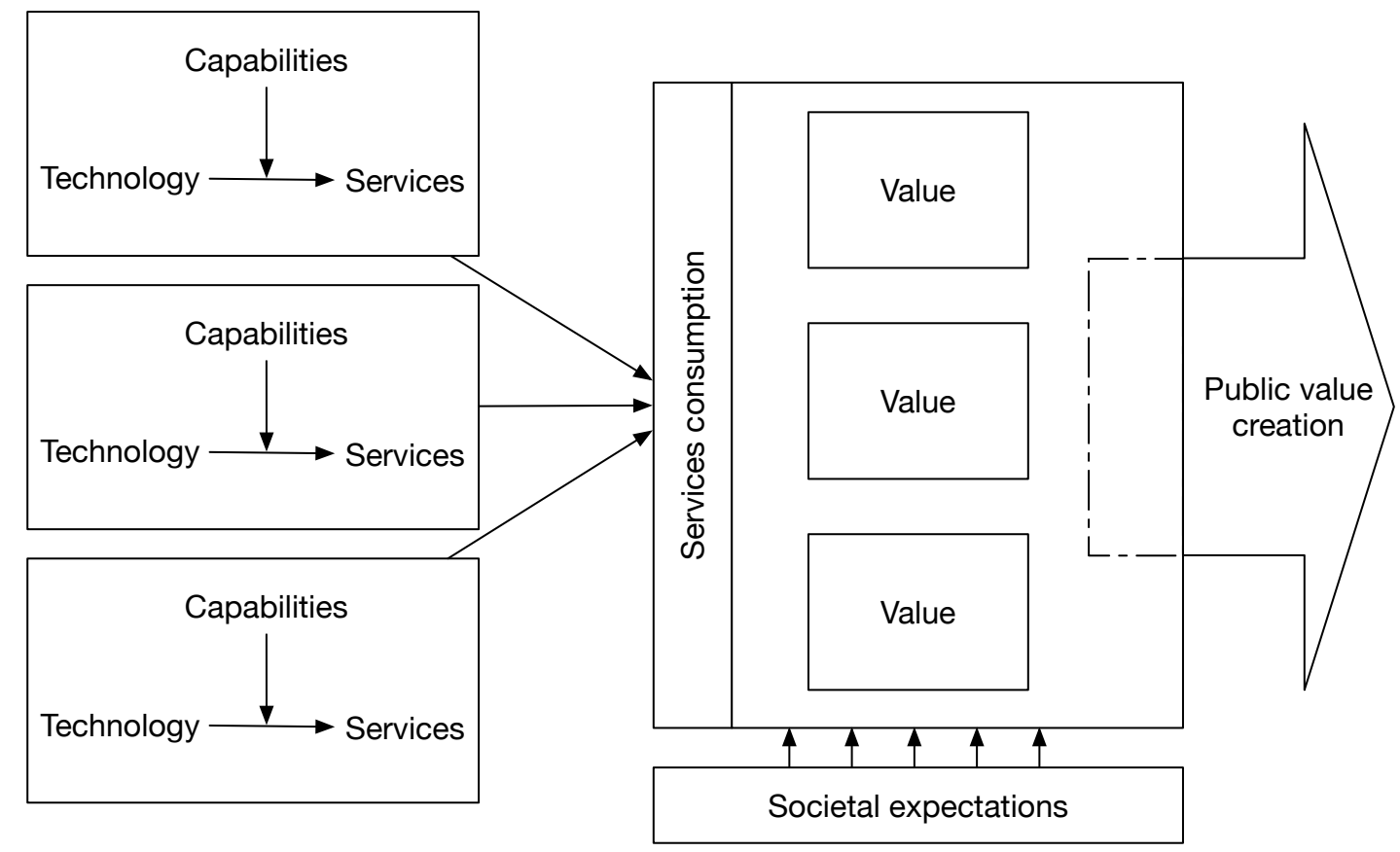

Figure 1 - Conceptual framework: the realm of public value creation 
The left side depicts the idea that digital technologies support and enhance public services, for example, in terms of efficiency, accessibility, ease of use, transparency, accountability and privacy - this aspect has been the focus of many studies in digital government. The production of each service is enabled by a configuration of the technologies and underpinning organizational capabilities that result from the systematic ability to deploy, integrate, and reconfigure internal and external resources. Capabilities can contribute to public value creation by permeating the boundaries between the various digital government implementations that may exist in relative isolation from each other. Due to institutional characteristics, resources, context and other factors, not all organizations can deploy all technologies, or develop all required capabilities. When capabilities cannot be developed internally, public organizations may need novel configurations of resources to acquire them externally, for example through co-creation, platform organizations, and other collaborative multi-actor arrangements in governance networks (e.g. Cabral et al., 2019; Crosby et al., 2017; Klievink et al., 2016). Organizational capabilities that depend on collaborative arrangements with external partners or networks may further limit options in public value provision; for example, in terms of openness of data, accountability, flexibility in the use of resources or high acquisition costs. The examples in sections 2.1 and 2.2 illustrate how complex digital government initiatives require dynamic capabilities to manage multiple service provisions and to enable public value creation while remaining responsive to changes in the environment.

Organizational capabilities and configurations shift the focus to achieving the best possible outcome of public value creation rather than optimizing the premise of each individual implementation of a technology or innovation. This is manifested when services enhanced by individual technologies and capabilities address possibly competing public values (de Graaf \& van der Wal, 2010; Rose et al., 2015). Such competing values provide different directions as to the deployment of technologies and organizational capabilities. For example, open data portals 'speak' to values such as transparency while the use of algorithms is increasingly negatively associated with accountability and other democratic values. Digital government initiatives like open data that are limited to a select number of participants require resources to install and uphold, which may come at the expense of equality and efficiency in other value categories. At the same time, better algorithms may boost efficiency and possibly effectiveness of public services. With the increasing variety of technologies in digital government, we would expect conflicting aspects and trade-offs to intensify and become more evident.

Following the production of each individual service, the combined consumption of all services results in the creation of different values as shown in the box in the middle of the figure and the arrow leading to the right side. Due to the aggregated effects, balances and trade-offs, public value creation cannot be fulfilled as a seamless accumulation of the different technologies and the values resulting from their use in the enhancement of services. In our view, public value (the singular) is what is created through the combined consumption of the multiple public services that are produced and enabled using digital technologies and other organizational arrangements 
(Cordella et al., 2017; Cordella \& Paletti, 2018). On the right hand side of the model, this outcome in terms of public value creation is a set of services provided through a specific configuration of technologies and capabilities. This configuration can extend to the interorganizational level; the combined configurations of multiple organizations that are aligned to deliver public value (e.g. not all develop the same capabilities but work with partners that have the capabilities).

Finally, as shown at the bottom of the framework, a core aspect of public value theory underlines meeting society's expectations in a constant balance between what public services deliver, how they are delivered and what society expects of them. Responding to societal expectations over time requires changes in the provision and enablers of public value creation so that they remain responsive to technological developments and societal expectations, especially when the two do not directly align. Even when digital government's positive effects in public value creation become evident, public expectations may change or diverge. The path to creating public value according to society's expectations comes through changing the configuration of public service consumption given the capabilities and technologies available. This further highlights how public value creation is an integrative challenge rather than one of implementation of new technologies.

Altogether, the conceptual framework depicts our integrative view although it does not intend to account for a complete mapping of public value creation processes which are further complicated and more specific to organizational and institutional contexts. The added view of bringing these perspectives together lies in a better understanding of their interrelated aspects in light of public value creation as a whole. To illustrate the practical implications, we can revisit the case of data analytics that promise enhancements in service delivery and various stages of policy and decision making processes (e.g. Van der Voort et al., 2019; Giest, 2017). As mentioned in section 2.2, while many government departments are in the process of building capabilities to achieve these benefits, resources that cannot be directed elsewhere might limit value creation through alternative paths. Much attention has to be devoted in understanding the values and trade-offs of these applications, whether pilot projects can scale up and which aspects to prioritise. In some cases, trade-off needs to be made between competing values, for example, between the effectiveness of risk-based policies supported by data analytics and their impacts on transparency and accountability. It is thus challenging to conceptualize the overall contribution of data analytics to public value from their combined outcomes.

Smart cities is another area that illustrates these concepts by bringing together a range of applications to improve the urban environment (e.g. Meijer 2017; Pereira et al. 2017). Each of the applications under the umbrella of smart cities will impact the delivery of individual values and public value creation as a whole in a local area. For example, public Wi-Fi services require organizational capabilities to procure the necessary hardware and software and collaborations with retailers, building owners and other stakeholders that are affected by the operation of the service. The values that come with providing Internet access in public spaces will be affected by the configuration of the service, the amount of resources deployed and its eventual uses and trade-offs (e.g. equal access and economic benefits but also cost, Wi-Fi tracking and use of data 
by third-parties). Depending on the configuration of the service - how public Wi-Fi will be deployed - the net balance on public value creation may change radically.

\section{Articles in the special issue}

The six articles published in the special issue went under a rigorous review process from an initial pool of 36 submissions. Each article provides its own context, methods and perspective on the broader theme of the special issue call. The review process stimulated interesting discussions between the 20 authors of the six articles, reviewers, and the editors that all shaped the intellectual development of the special issue. We consider it particularly positive to bring together articles that represent qualitative, quantitative and conceptual contributions. After introducing each article, we conclude the editorial note with directions for future research.

\subsection{Public value creation in the sharing economy}

The public sector's role in the sharing economy has been traditionally viewed as the regulatory body responsible for setting the framework for digital economic exchanges to take place. Hofmann, Sæbø, Braccini and Za argue that the sharing economy presents new challenges, opportunities and potential roles for the public sector while having significant implications for public values. Following a hermeneutic review of the literature, they identify the three additional roles of customer, service provider and platform provider that the public sector can fulfil in the sharing economy. Drawing on the lens of value positions (Rose et al., 2015), the article develops an analytical framework for understanding these roles and their considerable implications. The blending of value positions and new roles suggest that the public sector can become a more active and creative agent of the sharing economy and engage in the wider opportunities for value creation using public and private resources.

Such propositions support the importance of developing the necessary capabilities to be responsive in dynamic environments where public value creation shifts outside the internal boundaries of public management. This presents a considerable cultural and ideological change from the public sector's traditional role in public value creation and is consistent with calls to put public value at the center of the economy (Kattel \& Mazzucato, 2018; Mazzucato \& RyanCollins, 2019). Future studies could further explore the balances and trade-offs related to the new services that will be the outcomes of the public sector's new roles as an orchestrator of collaboration in the digital economy (Crosby, 't Hart, \& Torfing, 2017). 


\subsection{Applied value positions in automated decision making}

Automating decisions in social services using algorithmic applications promises gains in efficiency and even transparency while eliminating the discretionary practices and professional judgment of frontline officials. This sets the context for the article by Ranerup and Henriksen who examine value positions (Rose et al., 2015) as an explanatory lens in automated decisionmaking in social services in the local government of Trelleborg, Sweden. Motivated by the view that conflicts might occur between the value positions in practice, they present evidence of a balance between professionalism, efficiency and service when staff had to transition to this new system. Divergent value relationships did occur when case workers' decisions where automated and interactions with citizens were removed. In direct connection to our conceptual framework, the case analysis supports the view that benefits of digital applications viewed in isolation might lead to lack of consideration about trade-offs and possibly conflicting aspects of public value.

As the agenda of artificial intelligence progresses in the public sector, we could expect such conflicts to become more apparent in competition with existing processes. Conflicts in public value creation enabled by algorithmic governance could be identified in trade-offs between efficiency, fairness and transparency or other unintended consequences (e.g. Danaher et al., 2017; Janssen \& Kuk, 2016). This further highlights the importance of an integrative view of public value creation when new technologies and organizational capabilities result in enhancements in individual applications but affect public value creation in unexpected ways.

\subsection{Collaborative innovation and public value creation in smart cities}

Smart government applications usually present conditions where several stakeholders need to collaborate to produce or manage IT-enabled innovation. Neumann, Matt, Hitz-Gamper, Schmidthuber and Stürmer raise three important issues to set the context for their article: (1) it is not clear whether such collaborations are associated with business or public value creation, (2) potential conflicts and tradeoffs could occur, (3) there is more to learn about how collaborations should be managed to stimulate public value creation. Drawing on agency and stewardship theory, the authors develop a model that associates collaboration characteristics and their effects with public value creation. A multiple case study looks at collaborative innovation between local governments and utility companies in Switzerland. Examining these features in a variety of smart projects uncovers new aspects of the boundaries of business and public value creation while demonstrating the suitability of stewardship and agency relationships with local authorities.

As new applications are being flexibly integrated into a smart city ecosystem, local authorities have to develop the organizational capabilities to manage such collaborations and consider their contribution to public value creation from an integrated perspective. The analysis contributes to our thinking by showing how different types of relationships will have an impact on the values created by each collaboration and on public value creation as a whole. Neumann et al. emphasize 
the importance of close collaboration and stakeholder management capabilities which reinforces the call by Cabral et al. (2019).

\subsection{Configuring Government as a Platform for public value creation}

Government as a platform (GaaP) is an emerging configuration which can help governments to deliver public services better while increasing government efficiency. However, the nature of public services and the level of administrative control required to deliver the expected values define the most suitable characteristics the chosen platform configuration must provide. Since multiple services must be produced and different services require different characteristics in the supporting platform configuration, multiple platform configurations must be deployed, managed, and maintained to deliver all the needed public services. Cordella and Paletti discuss how these multiple platforms, or better a GaaP which is configured as a platform of platforms, shall be managed to better create public value. The proposed framework identifies orchestration as the key managerial action to be deployed to balance the values generated by the platform of platforms and hence support public value creation. The paper builds on a sound theoretical argumentation supported by the case of the Italian GaaP initiative.

As discussed by Cordella and Paletti, the increased diffusion of platforms and ecosystems in digital government increases the challenges of delivering public services that have conflictual impacts on public value creation. The modularity of platforms holds the promise to become more responsive to what the users of services want or need. It also facilitates co-production and can help bring together the distinct capabilities of multiple organizations to acquire the total set of capabilities necessary to realize a service. At the same time, such platforms may lower predictability of how individual technologies and services lead to value. The capability - perhaps a role even - of an orchestrator that safeguards the path to value creation, does seem to be an important step towards integration.

\subsection{Operational and strategic public value creation in cloud assimilation}

Cloud computing is a typical example of technologies that enable public value by providing the infrastructure for improved automation and data flow management for a range of other applications. The conceptual model and empirical study by Liang, Qi, Zhang and Li presents a contribution to the distinction of operational and strategic public value. Operational public value refers to internal benefits from the use of cloud applications while strategic public value refers to statements about the delivery of value outside the organization. A survey with 158 respondents in local and regional government in China measured the depth / breadth of cloud assimilation and the complementary / balanced strategic fit from organizational ambidexterity. As expected, a better developed cloud capability (assimilation) can improve operational public value by integrating isolated information within the organization and optimizing business processes. In 
turn, operational value explains a large amount of the variation in strategic value as does a complementary strategic fit, while a balanced fit does not show a significant effect.

Applications like cloud computing have multidimensional effects as enablers of dynamic capabilities that streamline existing applications and services through data storage and delivery. For example, by allowing service designers to have ubiquitous access to data or by improving security and reliability of services. The distinction between operational and strategic public value as modelled in the article reflects the relationship between internal operational efficiency and its strategic benefits that reach outside the organization. This could motivate more researchers to measure this distinction in relation to other applications, services and contexts. Furthermore, it demonstrates the role of complementarity of digital technologies from a public value perspective.

\subsection{Public and private value in citizen participation}

Whether framed as the engagement ideal (Rose et al., 2015) or public engagement capabilities (Pang et al., 2014), citizen-government interactions are an essential component of public value creation. Citizen participation entails both democratic, societal fairness and individual benefits that are reflected in citizens' motivations to take part in such processes. The article by Ju, Liu and Feng makes a distinction between private value acquisition and public value creation as fundamental motivations for citizens' participation from a social exchange perspective. The Green Commuting platform in Nanjing, China provides an interesting context to measure and explore this distinction using a survey with 269 participants. Although the participation of survey respondents is driven by both private and public value motivations, the determinants of each vary. The study has strong implications for the design of digital engagement from a public value perspective. It brings attention to the antecedents of participation and how they should be integrated into the features of platforms to stimulate value creation motivations beyond improving user experience elements (e.g. collective, monetary, gamification, public image and other incentives).

The distinction between public and private value demonstrates the aspect of responding to changing expectations about what constitutes public value creation and how to deliver it from an integrative perspective. Citizen's expectations about public value creation are reflected in the benefits they perceive from using applications like the Green Commuting platform. This distinction also has implications for public organizations that consider leveraging the capabilities they need to realize technology-supported services from the private sector.

\section{Conclusion and future research directions}

The special issue aims to provide a new point of reference on public value creation in digital government research. It brings together the six articles that tackle the issue from different angles with our theoretical perspective on integrative public value creation underpinned by technologies 
and organizational capabilities. We hope that the special issue will stimulate a more critical appreciation of public value and further research into a range of topics in the area that remain unexplored. We acknowledge the conceptual nature of this work and therefore welcome empirical and especially action-oriented research that can operationalize these perspectives and provide an action perspective for scholars and practitioners to consider the public value implications of digital government implementations.

The literature contains conceptual and empirical work on various public values, on how various digital innovations affect public values and which organizational capabilities are required to capitalize on those values. Many of the current studies have published on specific technologyvalues dyads, or focus on the applications thereof in specific cases and their observable outcomes. We call upon the community to consider that digital government technologies and innovations should not be treated in isolation from each other. Each has to be fitted into a complex situation, will interact with other technology-supported services, and may not have the public value implications that are reflected from the technological perspective alone. A more realistic perspective to studying public value creation is therefore one that looks at how this sits within the wider context of multiple technologies and applications.

In further directions for future research, our approach provides a starting point for mapping processes of public value creation in a topic that has received little attention (Alford \& Yates, 2014). Much further work can be achieved in considering which dynamic and operational capabilities can enable better performance and management of public value creation processes. The capabilities by Pang et al. (2014) provide a starting point together with the configurational approach (Wilden, Devinney, \& Dowling, 2016) and other new theoretical perspectives that can improve the relevance of capabilities in light of public value creation. Such an exploration can extend to capabilities that are not formulated directly by configuring internal government resources but include aspects such as (1) co-production, social or open innovation and other forms of involving digital or traditional publics, (2) the role of public administration networks, public-private partnerships and other relational approaches, (3) regulatory and policy initiatives to stimulate capability development. This could further inspire stage, maturity or readiness models that capture the transformation processes associated with public value creation including organizational capabilities and other enablers. Additional research can look into gaps in readiness, lack of capabilities, path dependencies, barriers or other organizational and institutional misalignments that inhibit public value creation.

Finally, with changing political, technological and societal expectations, the concept of public value creation may shift to new aspects for governments and policy makers. There are important directions to consider in the contextual and institutional differences of what constitutes public value creation, especially in emerging economies that have been much less explored (Twizeyimana \& Andersson, 2019). There are also significant opportunities to examine the new roles that governments and policy makers will fulfil in the creation and appropriation of public value and how these roles are enabled by digital government. 


\section{Acknowledgments}

We express our gratitude to Tomasz Janowski and Marijn Janssen for the opportunity to organize this special issue and for their guidance and support throughout the process. Our gratitude also goes to the authors and reviewers for their work and commitment to the special issue. We are further grateful to Frank Bannister for his insightful comments on the editorial. The editorial note represents only the views of the authors, all three of whom contributed equally to the ideas.

\section{References}

Alford, J, \& Hughes, O. (2008). Public Value Pragmatism as the Next Phase of Public Management. The American Review of Public Administration, 38(2), 130-148.

Alford, John, \& Yates, S. (2014). Mapping public value processes. International Journal of Public Sector Management, 27(4), 334-352.

Andersen, K. V., \& Henriksen, H. Z. (2006). E-government maturity models: Extension of the Layne and Lee model. Government information quarterly, 23(2), 236-248.

Bannister, F., \& Connolly, R. (2014). ICT, public values and transformative government: A framework and programme for research. Government Information Quarterly, 31(1), 119128.

Bannister, F., \& Connolly, R. (2015). The great theory hunt: Does e-government really have a problem? Government Information Quarterly, 32(1), 1-11.

Benington, J. (2007). From private choice to public value, In Benington, J. \& Moore, M. (editors), In search of public value-beyond private choice. Institute of Governance and Public Management (IGPM).

Benington, J., \& Moore, H. M. (2010). Public Value: Theory and Practice. Palgrave Macmillan.

Bonina, C.M. \& Cordella, A. (2008). The new public management, e-government and the notion of' public value': lessons from Mexico. Proceedings Annual Workshop of the AIS Special Interest Group for ICT in Global Development (GlobDev 2008).

Bruijn, H. De, \& Dicke, W. (2006). Strategies for safeguarding public values in liberalized utilitiy sectors. Public Administration, 84(3), 717-735.

Bryson, J. M., Crosby, B. C., \& Bloomberg, L. (2014). Public Value Governance: Moving Beyond Traditional Public Administration and the New Public Management. Public Administration Review, 74(4), 445-456.

Cabral, S., Mahoney, J. T., McGahan, A. M., \& Potoski, M. (2019). Value Creation and Value Appropriation in Public and Non-Profit Organizations. Strategic Management Journal, 40(4).

Chatfield, A. T., \& Reddick, C. G. (2018). Customer agility and responsiveness through big data analytics for public value creation: A case study of Houston 311 on-demand services. Government Information Quarterly, 35(2), 336-347. 
Cordella, A, \& Iannacci, F. (2010). Information Systems in the Public Sector: the e-Government Enactment Framework. Journal of Strategic Information Systems, 19(1), 52-66.

Cordella, A., \& Bonina, C. M. (2012). A Public Value Perspective for ICT Enabled Public Sector Reforms: a Theoretical Reflection. Government Information Quarterly, 29(4), 512-520.

Cordella, A., \& Paletti, A. (2018). ICTs and value creation in public sector: Manufacturing logic vs service logic. Information Polity, 23(2), 125-141.

Cordella, A., Paletti, A., \& Shaikh, M. (2017). Public Value and Co-Production: Reconfiguring Service Delivery. Academy of Management Proceedings, $2017(1), 10577$.

Cordella, A., \& Willcocks, L. (2012). Government policy, public value and IT outsourcing: The strategic case of ASPIRE. The Journal of Strategic Information Systems, 21(4), 295-307.

Criado, J. I., Sandoval-Almazan, R., \& Gil-Garcia, J. R. (2013). Government innovation through social media. Government Information Quarterly, 30(4), 319-326.

Crosby, B. C., 't Hart, P., \& Torfing, J. (2017). Public value creation through collaborative innovation. Public Management Review, 19(5), 655-669.

Dahl, A., \& Soss, J. (2014). Neoliberalism for the Common Good? Public Value Governance and the Downsizing of Democracy. Public Administration Review, 74(4), 496-504.

Danaher, J., Hogan, M. J., Noone, C., Kennedy, R., Behan, A., De Paor, A., ... Shankar, K. (2017). Algorithmic governance: Developing a research agenda through the power of collective intelligence. Big Data \& Society, 4(2).

de Graaf, G., \& van der Wal, Z. (2010). Managing Conflicting Public Values: Governing With Integrity and Effectiveness. The American Review of Public Administration, 40(6), 623630 .

De Jong, J., Douglas, S., Sicilia, M., Radnor, Z., Noordegraaf, M., \& Debus, P. (2017). Instruments of value: using the analytic tools of public value theory in teaching and practice. Public Management Review, 19(5), 605-620.

Eisenhardt, K. M., \& Martin, J. A. (2000). Dynamic Capabilities: What Are They? Source: Strategic Management Journal, 21(10/11), 1105-1121.

Estevez, E., \& Janowski, T. (2013). Landscaping government chief information officer education. In 2013 46th Hawaii International Conference on System Sciences (pp. 16841693). IEEE.

Giest, S. (2017). Big data for policymaking: fad or fast-track? Policy Sciences, 50(3), 367-382.

Günther, W. A., Rezazade Mehrizi, M. H., Huysman, M., \& Feldberg, F. (2017). Debating big data: A literature review on realizing value from big data. The Journal of Strategic Information Systems, 26(3), 191-209.

Hartley, J., Alford, J., Knies, E., \& Douglas, S. (2017). Towards an empirical research agenda for public value theory. Public Management Review, 19(5), 670-685.

Janssen, M., \& Helbig, N. (2016). Innovating and changing the policy-cycle: Policy-makers be 
prepared! Government Information Quarterly, 35(4), S99-S105.

Janssen, M., \& Kuk, G. (2016). The challenges and limits of big data algorithms in technocratic governance. Government Information Quarterly, 33(3), 371-377.

Jorgensen, T. B., \& Bozeman, B. (2007). Public Values: An Inventory. Administration \& Society, 39(3), 354-381.

Kankanhalli, A., Charalabidis, Y., \& Mellouli, S. (2019). IoT and AI for Smart Government: A Research Agenda. Government Information Quarterly, 36(2), 304-309.

Kankanhalli, A., Zuiderwijk, A., \& Tayi, G. K. (2017). Open innovation in the public sector: A research agenda. Government Information Quarterly, 34(1), 84-89.

Karkin, N., \& Janssen, M. (2013). Evaluating websites from a public value perspective: A review of Turkish local government websites. International Journal of Information Management, 34(3), 351-363.

Karunasena, K., \& Deng, H. (2012). Critical factors for evaluating the public value of egovernment in Sri Lanka. Government Information Quarterly, 29(1), 76-84.

Kattel, R., \& Mazzucato, M. (2018). Mission-oriented innovation policy and dynamic capabilities in the public sector. Industrial and Corporate Change, 27(5), 787-801.

Klievink, B., Bharosa, N., \& Tan, Y.-H. (2016). The collaborative realization of public values and business goals: Governance and infrastructure of public-private information platforms. Government Information Quarterly, 33(1), 67-79.

Klievink, B., \& Janssen, M. (2009). Realizing Joined-Up Government - Dynamic Capabilities and Stage Models for Transformation. Government Information Quarterly, 26(2), 275-284.

Linders, D. (2012). From e-government to we-government: Defining a typology for citizen coproduction in the age of social media. Government Information Quarterly, 29(4), 446454.

Mazzucato, M., \& Ryan-Collins, J. (2019). Putting value creation back into "public value”: from market-fixing to market-shaping. Retrieved from https:/www.ucl.ac.uk/bartlett/publicpurpose/publications/2019/jun/putting-value-creation-back-public-value-market-fixingmarket-shaping

McAfee, A., \& Brynjolfsson, E. (2012). Big data: the management revolution. Harvard Business Review, 90(10), 60-66, 68, 128.

Meijer, A. (2017). Datapolis: a public governance perspective on "smart cities". Perspectives on Public Management and Governance, 1(3), 195-206.

Mergel, I. (2019). Digital service teams in government. Government Information Quarterly, (advanced online publication). https://doi.org/10.1016/J.GIQ.2019.07.001

Mergel, I., Gong, Y., \& Bertot, J. (2018). Agile government: Systematic literature review and future research. Government Information Quarterly, 35(2), 291-298.

Moore, M., \& Khagram, S. (2004). On Creating Public Value Corporate Social Responsibility 
Initiative (No. 3).

Moore, M H. (1995). Creating Public Value: Strategic Management in Government. Cambridge, Massachusetts, USA: Harvard University Press.

Moore, Mark H. (2014). Public Value Accounting: Establishing the Philosophical Basis. Public Administration Review, 74(4), 465-477.

Niehaves, B., Plattfaut, R., \& Becker, J. (2013). Business process management capabilities in local governments: A multi-method study. Government Information Quarterly, 30(3), 217225.

Pablo, A. L., Reay, T., Dewald, J. R., \& Casebeer, A. L. (2007). Identifying, Enabling and Managing Dynamic Capabilities in the Public Sector. Journal of Management Studies, 44(5), 687-708.

Panagiotopoulos, P., Al-Debei, M. M., Fitzgerald, G., \& Elliman, T. (2012). A business model perspective for ICTs in public engagement. Government Information Quarterly, 29(2), 192202.

Pang, M.-S., Lee, G., \& DeLone, W. H. (2014). IT resources, organizational capabilities, and value creation in public-sector organizations: a public-value management perspective. Journal of Information Technology, 29(3), 187-205.

Pereira, G. V., Macadar, M. A., Luciano, E. M., \& Testa, M. G. (2017). Delivering public value through open government data initiatives in a Smart City context. Information Systems Frontiers, 19(2), 213-229.

Rose, J., Flak, L. S., \& Sæbø, Ø. (2018). Stakeholder theory for the E-government context: Framing a value-oriented normative core. Government Information Quarterly, 35(3), 362 374.

Rose, J., Persson, J. S., Heeager, L. T., \& Irani, Z. (2015). Managing e-Government: value positions and relationships. Information Systems Journal, 25(5), 531-571.

Scott, M., DeLone, W., \& Golden, W. (2016). Measuring eGovernment success: a public value approach. European Journal of Information Systems, 25(3), 187-208.

Teece, D. J., Pisano, G., Shuen, A., \& David Teece, M. J. (1997). Dynamic capabilities and strategic management. Strategic Management Journal, 187(18), 509-533.

Twizeyimana, J. D., \& Andersson, A. (2019). The public value of E-Government - A literature review. Government Information Quarterly, 36(2), 167-178.

UK Government. (2019a). A guide to using artificial intelligence in the public sector. Retrieved September 10, 2019, from https://www.gov.uk/government/collections/a-guide-to-usingartificial-intelligence-in-the-public-sector

UK Government. (2019b). Data science community. Retrieved August 25, 2019, from https:/www.gov.uk/service-manual/communities/data-science-community

UK Government Digital Service. (2019a). Government as a Platform - Government Digital Service. Retrieved August 20, 2019, from https://gds.blog.gov.uk/category/government-as- 
a-platform/

UK Government Digital Service. (2019b). Service Standard - Service Manual - GOV.UK. Retrieved August 20, 2019, from https://www.gov.uk/service-manual/service-standard

UK Government Digital Service. (2019c). User experience. Retrieved August 20, 2019, from https://gds.blog.gov.uk/tag/user-experience/

Voort, H. G. Van Der, Klievink, A. J., Arnaboldi, M., \& Meijer, A. J. (2019). Rationality and politics of algorithms. Will the promise of big data survive the dynamics of public decision making? Government Information Quarterly, 36(1), 27-38.

Wilden, R., Devinney, T. M., \& Dowling, G. R. (2016). The Architecture of Dynamic Capability Research Identifying the Building Blocks of a Configurational Approach. The Academy of Management Annals, 10(1), 997-1076.

Williams, I., \& Shearer, H. (2011). Appraising Public Value: Past, Present and Futures. Public Administration, 89(4), 1367-1384.

Y1ld1z, M., \& Saylam, A. (2013). E-government discourses: An inductive analysis. Government Information Quarterly, 30(2), 141-153.

Zuboff, S., \& Maxmin, J. (2002). The support economy: Why corporations are failing individuals and the next episode of capitalism. Penguin; New edition (3 Jun. 2004). 